sequent exposure to the virus. Furthermore, more severe reactions to infection with the virus have occurred after inoculation with respiratory syncytial virus vaccine. ${ }^{12}$

Although a recent retrospective study ${ }^{13}$ on 8 -year old children showed no difference in the prevalence of atopy between 26 patients who had had acute bronchiolitis in infancy and paired controls, its findings do not compare directly with those of the present study.

In studies of the connection between acute bronchiolitis and subsequent asthma Zweiman et $a l^{14}$ found retrospectively that $40-50 \%$ of children admitted to hospital because of acute bronchiolitis had recurrent wheeze subsequently and that the risk of this was higher when there was a family history of atopy or the patient showed other allergic manifestations. Bronchiolitis due to respiratory syncytial virus associated with subsequent wheezing was also found in a retrospective study by Rooney and Williams, ${ }^{2}$ in which $72 \%$ of those with recurrent wheeze had a family history of atopy. Hyde and Saed ${ }^{3}$ found that $39 \%$ of infants less than 1 year old who presented with bronchiolitis subsequently had a recurrent wheeze and that $78 \%$ of those had a family history of atopy or allergic manifestations. Given that childhood asthma is partly an allergic condition, the fact that a high proportion of those with acute bronchiolitis (particularly those with atopic features) have subsequent episodes of wheeze supports the view that acute bronchiolitis may occur more frequently in an atopic population.

We thank Dr W M McCrae and Dr W S Uttley for allowing us to include their patients in the study. We are also very grateful to Mrs D Tervit and Miss D McKay for their meticulous secretarial help in preparation of this paper.

Correspondence should be addressed to Dr Ian Laing, Royal Hospital for Sick Children, Sciennes Road, Edinburgh EH9 1LF.

\section{References}

${ }^{1}$ Ellis EF. Relationship between the allergic state and susceptibility to infectious airway disease. Pediatr Res 1977;11:227-9.

2 Rooney JC, Williams HE. The relationship between proved viral bronchiolitis and subsequent wheezing. I Pediatr 1971;79:744-7.

${ }^{3}$ Hyde JS, Saed AM. Acute bronchiolitis and the asthmatic child. $\mathcal{F}$ Asthme Res 1966;4:137-54.

${ }^{4}$ Eisen AH, Bacal HL. Relationship of acute bronchiolitis to bronchial asthma. Pediatrics $1963 ; 31: 859-61$.

${ }^{5}$ Matthew DJ, Norman AP, Taylor B, Turner MW, Soothill JF. Prevention of eczema. Lancet $1977 ; \mathrm{i}: 321-4$.

${ }^{6}$ Foucard T. A follow-up study of children with asthmatoid bronchitis. Acta Paediatr Scand 1973;62:633-44.

7 Whicher JT, Perry DE, Hobbs JR. An evaluation of the Hyland laser nephelometer PDQ system. Ann Clin Biochem 1978;15:77-85.

${ }^{8}$ Murray AB, Anderson DO. The epidemiologic relationship of clinical nasal allergy to eosinophils and to goblet cells in the nasal smear. fournal of Allergy $1969 ; 43: 1-8$.

${ }^{9}$ Berg T. The immunoglobulin development during the first year of life. Acta Paediatr Scand 1969;58:229-36.

${ }^{10}$ Berg T, Johansson SGO. Immunoglobulin levels during childhood with special regard to IgE. Acta Paediatr Scand 1969;58:513-24.

11 McIntosh K, Ellis EF, Hoffmann LS, Tillingast GL, Eller JJ, Fulginiti VA. The association of viral and bacterial respiratory infections with exacerbations of wheezing in young asthmatic children. $\mathcal{f}$ Paediatr 1973;82:578.

12 Kapikian AZ, Mitchell RH, Chanock RM, Shvedoff RA, Stewart CE. An epidemiological study of altered clinical reactivity to RSV infection in children previously vaccinated with an inactivated RS virus vaccine. Am $\mathcal{F}$ Epidemiol 1969;89:405.

${ }^{13}$ Sims DG, Gardner PS, Weightman D, Turner MW, Soothill JF. Atopy does not predispose to RSV bronchiolitis or post-bronchiolitic wheezing. Br Med $\mathcal{f} 1981$;282:2086-8.

14 Zweiman B, Schoenwetter WF, Pappano JE Jr, et al. Patterns of allergic respiratory disease in children with a past history of bronchiolitis. f Allergy Clin Immunol 1971 ;48:283-9.

(Accepted 27 fanuary 1982)

\title{
Nuclear magnetic resonance studies of forearm muscle in Duchenne dystrophy
}

\author{
RAYMOND J NEWMAN，PETER J BORE，LAWRENCE CHAN， DAVID G GADIAN, \\ PETER STYLES, DORIS TAYLOR, GEORGE K RADDA
}

\begin{abstract}
The forearms of six patients with Duchenne dystrophy were examined by the painless and non-invasive technique of high-resolution nuclear magnetic resonance spectroscopy. The phosphorus spectrum was abnormal in that the ratios of phosphocreatine to adenosine triphosphate
\end{abstract}

\footnotetext{
Nuffield Department of Orthopaedic Surgery, Nuffield Orthopaedic Centre, Oxford OX3 7LD

RAYMOND J NEWMAN, BSC, FRCS, research fellow and honorary senior registrar

Department of Biochemistry, University of Oxford, Oxford OX1 3QU

PETER J BORE, BSC, FRCS, research fellow

DAVID G GADIAN, MA, DPHIL, research fellow

PETER STYLES, BSC, research assistant

DORIS TAYLOR, DPHIL, research assistan

GEORGE K RADDA, DPHIL, FRS, lecturer
}

Nuffield Department of Medicine, University of Oxford, John Radcliffe Hospital, Oxford OX3 9DU

LAWRENCE CHAN, MB, MRCP, clinical lecturer and to inorganic phosphate were reduced. Absolute quantification under the conditions of this experiment was not possible but it was probable that in dystrophy the concentration of phosphocreatine in muscle was appreciably reduced. A signal in the phosphodiester region of the spectrum was recorded consistently in patients with dystrophy but not in controls. The intracellular pH of the muscle in the dystrophic patients was abnormally alkaline.

The clinical application of nuclear magnetic resonance spectroscopy remains to be proved, but it appears to be a promising non-invasive technique for investigating biochemical abnormalities of muscle disease.

\section{Introduction}

The muscular dystrophies are characterised by progressive degeneration of muscle but not affecting the nervous system. The commonest form is Duchenne dystrophy, which is transmitted by an X-linked recessive gene. Signs of the disease usually appear within the first three years of life and are most noticeable in the legs. An initial enlargement of the muscles gives way to profound weakness and wasting, and death from inanition or 
cardiac or ventilatory failure occurs by the middle of the second decade.

The first biochemical defect to be discovered in the condition -namely, a decrease in urinary creatine excretion-was noted over 100 years ago. ${ }^{1}$ Since then further abnormalities have been described; and some are accepted as diagnostic criteria. Unfortunately most measurements are invasive and therefore complicated.

It is now possible to observe the energy metabolism of human muscle in vivo but non-invasively using high-resolution phosphorus nuclear magnetic resonance spectroscopy. ${ }^{2}$ This has resulted from progress in magnet technology leading to the construction of powerful magnets that can accommodate a human limb. Also the introduction of surface coils ${ }^{3}$ and field profiling ${ }^{4}$ have permitted an appreciable degree of spatial resolution.

We describe the clinical application of this technique to the study of Duchenne dystrophy.

\section{Patients and methods}

The table gives details of six children with Duchenne dystrophy who were examined by nuclear magnetic resonance spectroscopy. In all cases the diagnosis was by a consultant physician and corroborated by a mu: le b.opsy. ${ }^{5}$ Since nuclear magnetic resonance had been introduced into clinical practice only during the past year, ethical approval was sought and informed consent obtained from the patients' parents. No special preparation of the subjects was required.

The TMR-32 Fourier transform spectrometer used a 1.9 tesla superconducting magnet with a bore of $20 \mathrm{~cm}$ (Oxford Research Systems) and operated at $32.5 \mathrm{MHz}$ for phosphorus ( ${ }^{31} \mathrm{P}$ ) and 80.285 $\mathrm{MHz}$ for protons $\left({ }^{1} \mathrm{H}\right)$. The radiofrequency coil which detected the signals was wound from $3 \mathrm{~mm}$ copper wire. It was rectangular
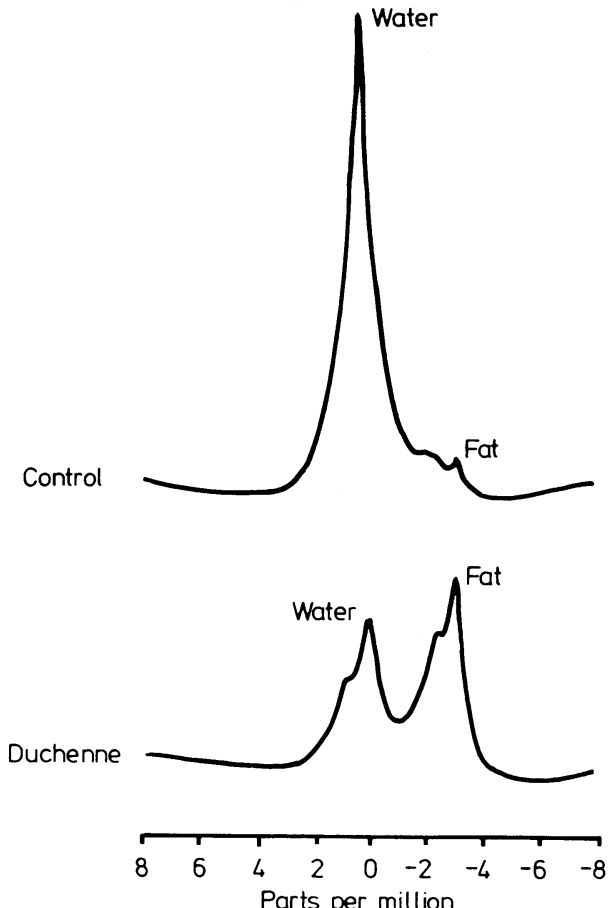

FIG 1-Proton nuclear magnetic resonance spectra of control and dystrophic subjects plotted on same scales. Each spectrum represents sum of four scans recorded using $75 \mu$ s radiofrequency pulses of $80 \cdot 285 \mathrm{MHz}$ at one-second intervals. Broad components of spectrum eliminated by convolution difference using line broadenings of 6 and $100 \mathrm{~Hz}$ together with multiplication factor of $0 \cdot 8$. Chemical shifts defined as positive in high-frequency direction with water peak chosen as internal chemical shift standard.

Clinical details of patients with Duchenne dystrophy

\begin{tabular}{|c|c|c|c|c|c|}
\hline $\begin{array}{l}\text { Case } \\
\text { No }\end{array}$ & $\begin{array}{c}\text { Age } \\
\text { (years) }\end{array}$ & $\begin{array}{c}\text { Arm } \\
\text { examined }\end{array}$ & $\begin{array}{l}\text { Family history } \\
\text { of dystrophy }\end{array}$ & $\begin{array}{l}\text { Ability to } \\
\text { walk }\end{array}$ & Muscle power in arms \\
\hline $\begin{array}{l}1 \\
2 \\
3 \\
4\end{array}$ & $\begin{array}{l}15 \\
15 \\
13 \\
11\end{array}$ & $\begin{array}{l}\text { Right } \\
\text { Left } \\
\text { Right } \\
\text { Right }\end{array}$ & $\begin{array}{c}\text { No } \\
\text { One affected brother } \\
\text { No } \\
\text { No }\end{array}$ & \multirow{2}{*}{$\begin{array}{c}\text { No } \\
\text { No } \\
\text { No } \\
\text { With help but falls } \\
\text { frequently } \\
\text { No } \\
\text { No }\end{array}$} & $\begin{array}{l}\text { Can just raise hands from thighs } \\
\text { Can just raise hands from thighs } \\
\text { Can raise hands to waist height } \\
\text { Can raise hands to shoulder height }\end{array}$ \\
\hline $\begin{array}{l}5 \\
6\end{array}$ & $\begin{array}{r}11 \\
9\end{array}$ & $\begin{array}{l}\text { Right } \\
\text { Right }\end{array}$ & $\begin{array}{l}\text { No } \\
\text { No }\end{array}$ & & $\begin{array}{l}\text { Can raise hands to waist height } \\
\text { Can raise hands to waist height }\end{array}$ \\
\hline
\end{tabular}

$(75 \times 65 \mathrm{~mm})$ but contoured to fit closely the middle third of the flexor aspect of the forearm. Before the collection of data it was tuned to the resonance frequencies of both phosphorus and hydrogen and the homogeneity of the magnetic field optimised. Proton spectra were recorded at rest by adding signals over four seconds, but for phosphorus studies data collection was continued for 30 minutes to achieve a satisfactory ratio of signal to noise.

No harmful effects of static magnetic fields of 1.9 tesla have been described but it was not considered justifiable to examine normal children as controls. The same protocol was therefore followed in five healthy men aged 29-37 years. No ill effects were noted either during or after the examination, which lasted about 45 minutes.

\section{Results}

Figures 1 and 2 show proton and phosphorus nuclear magnetic resonance spectra from the forearm at rest. At least five abnormalities were apparent in those of the patients with dystrophy.

Firstly, the ratios of the signal intensities of the phosphoruscontaining metabolites were disordered. That of phosphocreatine to $\beta$-adenosine triphosphate was $1.3 \pm 0.4(\mathrm{SD})$ in the patients with dystrophy compared with $2 \cdot 7 \pm 0 \cdot 4$ in the controls. The phosphocreatine to inorganic phosphate ratio was low at $2 \cdot 1 \pm 0 \cdot 8$ compared with $18 \cdot 0+7 \cdot 0$ in the normal subjects. Under different experimental conditions this control value is somewhat lower. The relative areas of the peaks of phosphocreatine and inorganic phosphate may be accepted as equivalent to the relative tissue concentrations of these metabolites.
Nevertheless, since phosphocreatine and adenosine triphosphate are subject to different degrees of magnetic saturation ${ }^{6}$ the concentration ratios of these compounds to each other were underestimated by about $30 \%$

Secondly, though the technique was not quantitative under the conditions of the experiment, probably both phosphocreatine and adenosine triphosphate were present in reduced amounts. If the water signal arose exclusively from muscle, division of the intensities of the phosphocreatine and adenosine triphosphate signals by the intensity of the corresponding water peak would give an index (in arbitary units) of their concentrations in muscle tissue. For phosphocreatine this value was $0 \cdot 16 \pm 0.05$ in the controls and $0.03 \pm 0.02$ in the patients. Similarly, the control index for adenosine triphosphate of $0.07 \pm 0.03$ was reduced in dystrophy to $0.02 \pm 0.01$. These figures suggested a $5 \cdot 5$-fold reduction in the phosphocreatine concentration and a 3.5-fold reduction in adenosine triphosphate, but only if the water signal arose solely from muscle. Patients whose dystrophy is as advanced as those in this series have a large proportion of their muscle replaced by fat; this is likely to contribute appreciably to the water signal, and the values of 5.5 and 3.5 represent upper limits only. Adenosine triphosphate concentration may be unchanged in dystrophy but most probably the phosphocreatine concentration is reduced.

Thirdly, a peak was consistently identified in the patients with dystrophy that was not seen in the controls. It was recorded between the signals of inorganic phosphate and phosphocreatine and varied in position from 2.3 to 3.3 parts per million (ppm) (all peak positions quoted relative to phosphocreatine). The signal bore an intensity ratio to that of phosphocreatine of $0 \cdot 3 \pm 0 \cdot 1$. 
Fourthly, the position of the inorganic phosphate peak was used as an index of intracellular $\mathrm{pH} .{ }^{7}$ In the patients this was $7 \cdot 19 \pm 0 \cdot 07$, which differed significantly from the $7.04 \pm 0.05$ in the controls $(\mathrm{p}<0.01)$.

Lastly, the signal from fat tissue was particularly intense in the patients, which was in keeping with the known processes of Duchenne dystrophy.

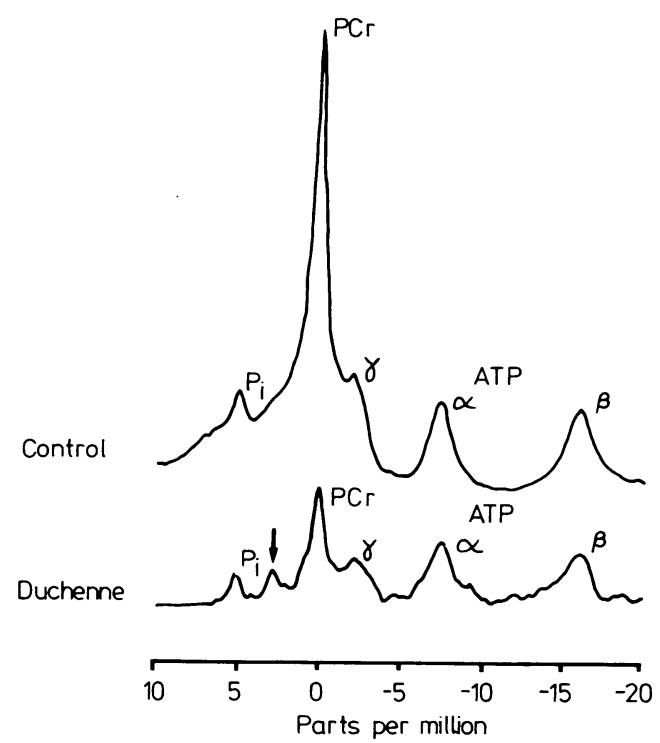

FIG 2-Phosphorus nuclear magnetic resonance spectra of control and dystrophic subjects with amplitude of dystrophic spectrum doubled for clarity of presentation. Each spectrum represents sum of 2048 scans recorded using $75 \mu \mathrm{s}$ radiofrequency pulses of $32.5 \mathrm{MHz}$ at one-second intervals. Convolution difference and chemical shifts as in fig 1, but phosphocreatine chosen as internal chemical shift standard.

$\mathrm{PCr}=$ Phosphocreatine. $\mathrm{P}_{\mathrm{i}}=$ Inorganic phosphate. $\alpha, \beta$, and $\gamma$ refer to $\alpha-, \beta$-, and $\gamma$-phosphate groups of adenosine triphosphate. Arrow indicates additional peak seen in Duchenne dystrophy.

\section{Discussion}

In the past it has proved difficult to manufacture wide-bore magnets with sufficiently homogeneous magnetic fields and the study of dystrophic muscle by nuclear magnetic resonance spectroscopy has been restricted to examining extracts of biopsy material. ${ }^{8}$ The spectrum of a perchloric acid extract of dystrophic chicken pectoralis contained signals from both glycerol-3phosphorylcholine and serine ethanolamine phosphodiester, but this was not seen in the spectra of extracts of healthy chickens. Nuclear magnetic resonance examination of perchloric acid extracts of normal human quadriceps, however, showed a glycerol-3-phosphorylcholine peak that was not recorded from Duchenne muscle.

Since the nuclear magnetic resonance study of human muscle is now possible in vivo, the results are not complicated by artefacts resulting from biopsy technique, postmortem change, or chemical extraction. It is therefore interesting that a peak that varied in position in the spectrum from 2.3 to $3.3 \mathrm{ppm}$ was consistently identified in the patients with Duchenne dystrophy but not in the control subjects. Signals from serine ethanolamine phosphodiester and glycerol-3-phosphorylcholine occur at $2 \cdot 8$ and $3.1 \mathrm{ppm}$, respectively, but in the absence of formal chemical identification we cannot conclude that these were the compounds responsible for the additional peaks seen in the patients with dystrophy.

The finding of reduced muscle concentrations of phosphocreatine and adenosine triphosphate in Duchenne dystrophy ${ }^{9}$ is no longer universally accepted, since the published figures may represent no more than a dilution of muscle by fat. This is because the reduction in adenosine triphosphate is not pronounced when observed against an internal standard such as total creatine ${ }^{10}$ or myosin. ${ }^{11}$ Our findings agree with reports of a pronounced drop in the muscle phosphocreatine concentration but cannot confirm a significant reduction in adenosine triphosphate concentration.

The resting intracellular $\mathrm{pH}$ of the control subjects in this study was $7.04 \pm 0.05$ and agreed with that of our larger control series. The $\mathrm{pH}$ of the patients, however, was abnormally alkaline at $7 \cdot 19 \pm 0 \cdot 08$. To our knowledge this measurement has not been recorded before.

The abnormalities described here may have been due at least in part to the difference in age between the patients and controls. Nevertheless, several children with glycolytic enzyme deficiencies, mitochondrial myopathies, and undiagnosed muscle weakness have been examined with this technique and none has displayed the changes seen in dystrophy. We are continuing our nuclear magnetic resonance study of a wide variety of muscle diseases, and not until this has been completed can we suggest that the abnormalities presented here are diagnostic of Duchenne dystrophy.

The clinical application of nuclear magnetic resonance spectroscopy is still developmental, but none the less it holds great promise as a non-invasive technique for investigating the biochemical abnormalities underlying muscle disease.

We thank the British Heart Foundation and the Medical Research Council for financial help; Dr G M Cochrane, of the Nuffield Orthopaedic Centre, for allowing us to study patients under his care; Mrs Yvonne Green and Miss Judith Harley for technical work; Mrs Sandra Newman and Mrs Mary Wood for typing the manuscript; and the departments of medical illustration and photography, Nuffield Orthopaedic Centre, for the figures. LC is supported by the Muscular Dystrophy Association of New York.

\section{References}

${ }^{1}$ Rosenthal M. Hanbuch der Diagnostik und Therapie der Nervenkrankheiten. Erlangen: Enke, 1870

${ }^{2}$ Ross BD, Radda GK, Gadian DG, Rocker G, Esiri M, Falconer-Smith J. Examination of a suspected case of McArdle's syndrome by ${ }^{31} \mathrm{P}$ nuclear magnetic resonance. $N$ Engl f Med $1981 ; 304: 1338-42$.

${ }^{3}$ Ackerman JJH, Grove TH, Wong GG, Gadian DG, Radda GK. Mapping of metabolites in whole animals by ${ }^{31} \mathrm{P}$ NMR using surface coils. Nature $1980 ; 283: 167-70$.

4 Gordon RE, Hanley PE, Shaw D, et al. Localisation of metabolites in animals using ${ }^{31} \mathrm{P}$ topical magnetic resonance. Nature $1980 ; 287: 367-8$.

${ }^{5}$ Dubowitz V, Brooke MH. Muscle biopsy: a modern approach. London: Saunders, 1973.

${ }^{6}$ Gadian D, Radda GK, Ross B, et al. Examination of a myopathy by phosphorus nuclear magnetic resonance. Lancet 1981 ;ii :774-5.

${ }^{7}$ Moon RB, Richards JH. Determination of intracellular $\mathrm{pH}$ by ${ }^{31} \mathrm{P}$ magnetic resonance. F Biol Chem 1973;248:7276-8.

${ }^{8}$ Chalovich JM, Burt TB, Danon MJ, Glonek T, Barany M. Phosphodiesters in muscular dystrophies. Ann NY Acad Sci 1979;317:649-69.

9 Thompson WH, Smith I. X-linked recessive (Duchenne) muscular dystrophy (DMD) and purine metabolism: effects of oral allopurinol and adenylate. Metabolism 1978;27:151-63.

${ }^{10}$ Edwards RHT. Energy metabolism in normal and dystrophic human muscle. In: Rowland LP, ed. Pathogenesis of human muscle dystrophies. Amsterdam: Excerpta Medica, 1977:415-28.

11 Samaha FJ, Davis B, Nagy B. Duchenne muscular dystrophy: adenosine triphosphate and creatine phosphate content in muscle. Neurology (Minneap) 1981 ;31:916-9.

(Accepted 11 fanuary 1982)

\section{OF THE APOPLEXY.}

THE apoplexy is a fudden lofs of fenfe and motion, wherein the patient is to all appearance dead; the heart and lungs however ftill continue to move. Though this difeafe proves often fatal, yet it may fometimes be removed by proper care. It chiefly attacks fedentary perfons of a grofs habit, who ufe a rich and plentiful diet, and indulge in ftrong liquors. People in the decline of life are moft fubject to the apoplexy. It prevails moft in winter, efpecially in rainy feafons, and very low ftates of the barometer.

(Buchan's Domestic Medicine, 1786.) 